TITLE:

\title{
Floral synomone diversification of sibling Bulbophyllum species (Orchidaceae) in attracting fruit fly pollinators
}

AUTHOR(S):

Nakahira, Masataka; Ono, Hajime; Wee, Suk Ling; Tan, Keng Hong; Nishida, Ritsuo

\section{CITATION:}

Nakahira, Masataka ... [et al]. Floral synomone diversification of sibling Bulbophyllum species (Orchidaceae) in attracting fruit fly pollinators. Biochemical Systematics and Ecology 2018, 81: 86-95

\section{ISSUE DATE:}

2018-12

URL:

http://hdl.handle.net/2433/235528

\section{RIGHT:}

(c) 2018. This manuscript version is made available under the CC-BY-NC-ND 4.0 license

http://creativecommons.org/licenses/by-nc-nd/4.0/:; The full-text file will be made open to the public on 01 December 2019 in accordance with publisher's 'Terms and Conditions for Self-Archiving'.; この論文は出版社版でありません。引 用の際には出版社版をご確認ご利用ください。; This is not the published version. Please cite only the published version. 


\section{Floral Synomone Diversification of Bulbophyllum Sibling Species (Orchidaceae) in Attracting Fruit Fly Pollinators}

Masataka Nakahira $^{a} \cdot$ Hajime Ono $^{a} \cdot$ Suk Ling Wee ${ }^{b, c} \cdot$ Keng Hong Tan ${ }^{d}$ Ritsuo

\section{Nishida ${ }^{a}, *$}

*Corresponding author

Ritsuo Nishida

ritz@kais.kyoto-u.ac.jp

${ }^{a}$ Laboratory of Chemical Ecology, Graduate School of Agriculture, Kyoto University, Kyoto 6068502, Japan

b School of Environmental and Natural Resource Sciences, Faculty of Science and Technology, Universiti Kebangsaan Malaysia, 43600 Bangi Selangor Darul Ehsan, Malaysia

${ }^{c}$ Centre for Insect Systematics, Faculty of Science and Technology, Universiti Kebangsaan Malaysia, 43600 Bangi Selangor Darul Ehsan, Malaysia

d Tan Hak Heng Co., Johor Bahru, Johor, Malaysia 
Abstract Floral scent is one of the crucial cues to attract specific groups of insect pollinators in angiosperms. We examined the semiochemical diversity in the interactions between "fruit fly orchids" and their pollinator fruit fly species in two genera, Bactrocera and Zeugodacus (Tephritidae: Diptera). Two known attractants for the Dacini fruit flies, methyl eugenol (ME) and raspberry ketone (RK), have been identified from the Bulbophyllum orchids. Additionally, zingerone (ZN), with a hybrid chemical structure between ME and RK, and attracts both ME- and RK-sensitive fly species, was also identified. Male flies utilize the floral scent as sex pheromone precursor or components to attract conspecific females and gain mating advantage. We analyzed the floral components of two sibling orchids, Bulbophyllum macranthum collected from Southeast-Asian countries and Bu. praetervisum collected from Sabah, Malaysia. For Bu. macranthum, the major floral component from Malaysia and Thailand was identified as ZN; whereas that from the Philippines was ME. For Bu. praetervisum, RK was found as the major constituent, but chemical profiles of the attractants were different among individuals, i.e. in addition to $\mathrm{RK}, \mathrm{ZN}$ was also found in some of the Bu. praetervisum flowers; and one of the specimens contained ME besides RK and ZN. These differences in fruit fly-attracting floral scents shown by the sympatric chemotypes of Bu. praetervisum are contrary to that shown by the allopatric chemotypes of $B u$. macranthum, demonstrating the versatility in the floral synomone biosynthetic processes. Phylogenetic analysis using chloroplast DNA shows that the Malaysia- and Thailand-chemotypes of Bu. macranthum and Bu. praetervisum belong to the same lineage, although their chemical profiles are distinctly different. This demonstrates that diversification of floral synomone may happen even within a putative orchid species in order to attract a wider community of fruit fly pollinators from different genera to maximize pollination success.

Keywords Bulbophyllum macranthum, Bulbophyllum praetervisum, Daciniphilous orchids, Floral volatiles, Phenylpropanoids, Phenylbutanoids

\section{Introduction}

Floral scent is a key determinant of the diversity and abundance of insect visitors and/or pollinators of flowers (Dobson, 1994; Raguso, 2001). Evolutionary changes in floral traits, volatile chemical profiles in particular, will likely influence types of floral visitors, resulting in a shift in the associated pollinator assemblage (Okamoto et al., 2015; Peakall et al., 2010; cf. Van der Niet et al., 2014). However, pollinators may also be key factors driving floral divergence and eventually leading to plant speciation (Johnson and Steiner, 2000). Thus, changes in the biosynthesis of floral semiochemicals could have reciprocal impacts on plant-insect interactions. The process in which a change of floral chemical profiles within the same or very closely related species is associated with a 
consequent change of pollinators is well documented for the sexually deceptive orchids (Ayasse et al., 2011; Bohman et al., 2014).

The interaction of fruit fly species in two genera - Bactrocera and Zeugodacus (formerly a subgenus of Bactrocera) - in the tribe Dacini (Tephritidae: Diptera) with "fruit fly orchids" via floral scents is a suitable case to examine a variation of chemical profiles of flowers in association with a possible pollinator shift. The two fruit fly genera comprise more than 500 identified indigenous species centered in the Southeast Asian and Northern Oceanian regions and overlap with the habitat and distribution of fruit fly orchids. Some of these species were formerly categorized by males' affinity to either methyl eugenol (ME; a phenylpropanoid) or raspberry ketone (RK; a phenylbutanoid) (or its acetyl derivative, cue-lure (CL)) (Metcalf, 1990; Tan and Nishida, 2012; Tan et al., 2014). The males are strongly attracted to various plant sources containing ME or RK to acquire sex pheromonal components or precursors to attract conspecific females and/or allomones (defense substances) for protection against predators (Nishida et al., 1990; Tan and Nishida, 1998; Wee and Tan, 2001). While males of ca 80 Dacini fruit fly species, including Ba. carambolae Drew \& Hancock, Ba. dorsalis (Hendel) and Ba. umbrosa (Fabricius), are sensitive to ME, males of another ca 200 related species, such as Ba. albistrigata de Meijere, Ba. melastomatos Drew \& Hancock, Z. caudatus (Fabricius), Z. cucurbitae (Coquillett) and Z. tau (Walker), are sensitive to RK (Tan et al., 2014). A number of orchid species in the Section Sestochilus Benth. \& Hook. f. in the genus Bulbophyllum (Orchidaceae), which are endemic and distributed widely in Southeast Asia and Northern Oceania regions, selectively attract these fruit fly males as specific pollinators by emitting the male-attracting volatile - either ME or RK. Zingerone (ZN; a phenylbutanoid) (4-(4-hydroxy-3-methoxyphenyl)-2-butanone) has also been identified as a unique floral component that attracts both ME-sensitive and RK-sensitive species (Tan and Nishida, 2000). These "daciniphilous" (formerly bactrocerophilous; see Tan and Nishida, 2013) Bulbophyllum orchid species were broadly classified into three groups based on their major floral volatiles:

i) ME-producing species: Bu. cheiri (Nishida et al., 2004; Tan et al., 2002); Bu. vinaceum (Tan et al., 2006);

ii) RK-producing species: Bu. apertum (syn. Bu. ecornutum) (Tan and Nishida, 2005); and

iii) ZN-producing species: Bu. patens (Tan and Nishida, 2000); Bu. baileyi (Tan and Nishida, 2007)

In the Southeast Asia and Northern Oceania regions, the distribution of daciniphilous orchids overlaps with the habitats of indigenous Dacini fruit fly species that are strongly attracted to ME, RK or $\mathrm{ZN}$. These floral volatiles were found to play an important role in the mutualistic interaction between the orchids and fruit flies (Tan et al., 2014). 
Over a hundred years ago, Henry Ridley (1890) first described the process of pollination in a daciniphilous orchid, Bu. macranthum Lindl. (Fig. 1A), in which the non-resupinate flower mechanically trapped a pollinator fly with slippery lateral sepals and a mobile lip. He reported that the flowers possessed a strong scent, similar to that of cloves or Turkey rhubarb, that likely navigated the fly. Although the fly species was not identified, he observed that the same fly species visited flowers of Dendrobium anosmum Lindl. (syn. D. superbum). Since the flowers of this species attract males of the melon fly, Z. cucurbitae, with a sweet scent of RK (Nishida et al., 1993), it has been assumed that $B u$. macranthum also emits RK and thereby the fly species he observed on Bu. macranthum was probably either Z. cucurbitae or another species sensitive to RK. However, our field observations of visiting flies and chemical analyses of the floral volatiles revealed a more complex system than initially predicted. Variation of floral volatile components within the same orchid species and the pollinating fruit fly species appear to reflect the possible pollinator shift within the tribe, Dacini. Thus, we investigated the chemical constituents responsible for fruit fly attraction in several chemotypes of Bu. macranthum and its very close sibling species, Bu. praetervisum J. J. Verm. (Fig. 1B).

In orchids, instead of producing enormous amounts of powdery pollen grains, a relatively large pollinarium, bearing pollinia containing very fine pollens, is carried by a highly reliable and specific pollinator (Nilsson, 1992) (Fig. 1C). Thus, the pollinarium is known as a key innovation in the evolutionary radiation of orchids (Johnson and Edward, 2000). Many orchids deceive pollinators by producing odors that mimic food or sex pheromone to bring them to the floral reproductive organs without providing rewards (Dobson, 1994; Jasáková and Kindlmann, 2006; Ong and Tan, 2011). In euglossine bee-orchid interactions, the males positively accumulate terpenoid and aromatic volatiles from the flowers, but it has not been fully understood how these floral fragrances are used by the male bees (Dressler, 1982; Pokorny et al., 2017; Zimmermann et al., 2006). However, in the case of daciniphilous orchid-fruit fly interactions, the flowers supply the sex pheromone/allomone materials to the male flies as a reward for aiding pollination. Since these Dacini males positively accumulate floral phenylpropanoids/phenylbutanoids in the rectal pheromone gland as sex pheromone to attract conspecific females (reviews, Shelly, 2010; Tan et al., 2002, 2006, 2014), the floral attractant is defined as synomone - a released semiochemical benefitting both interacting organisms (Nordlung and Lewis, 1976). This further reinforces the true mutualistic relationship between flowers and fruit fly pollinators. 


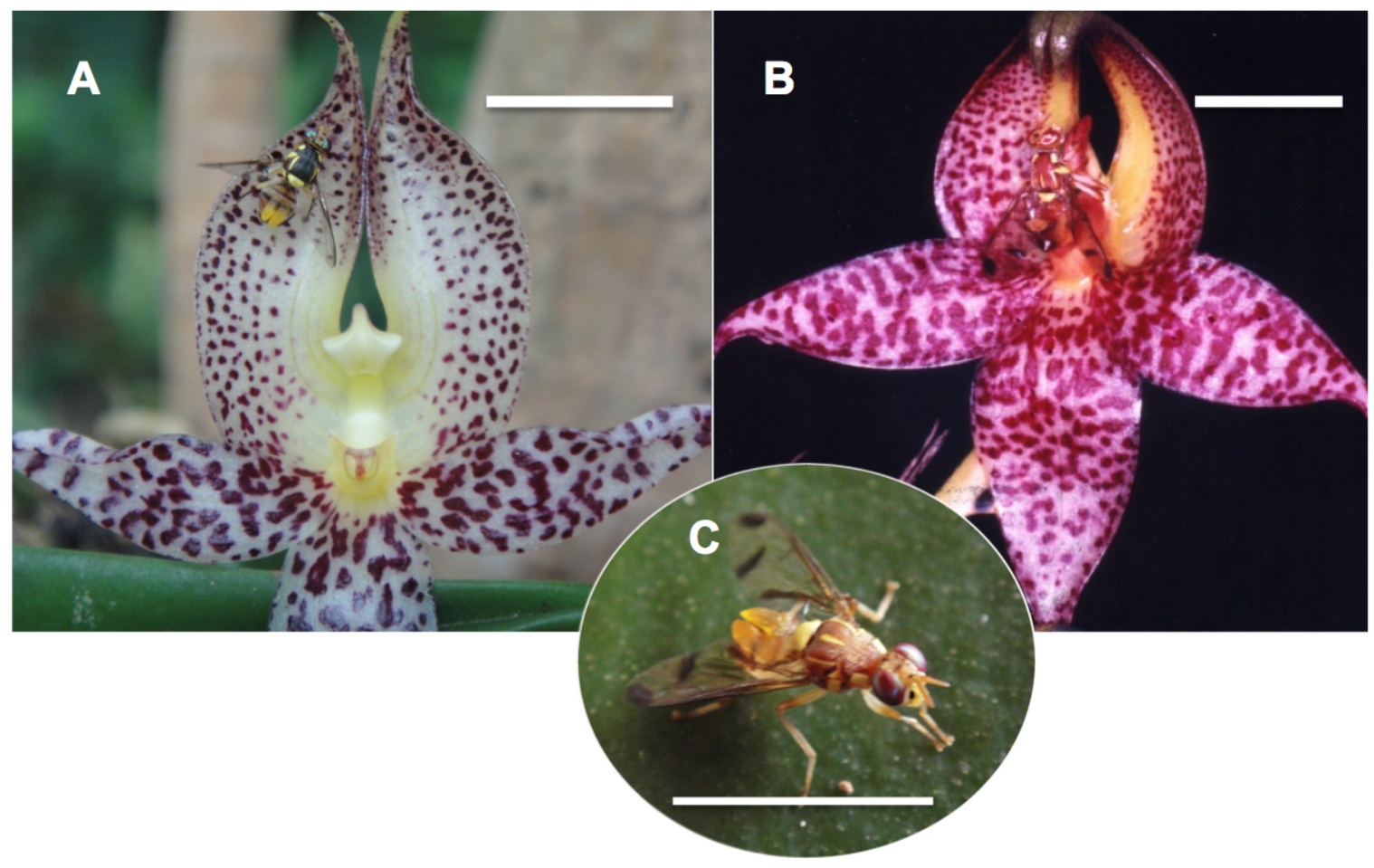

Fig. 1. A) A flower of Bulbophyllum macranthum (Malaysia-chemotype) visited by a Bactrocera dorsalis male bearing the pollinia on its abdominal dorsum; B) Bu. praetervisum (Malaysiachemotype) flower visited by a $Z$. cucurbitae male being stuck to the floral column via viscidium before pollinia removal from the anther (right); C) A Z. cucurbitae male bearing pollinia of $B u$. praetervisum. Bar $=10 \mathrm{~mm}$.

The males of several ME-sensitive pollinator fruit fly species have been known to positively acquire sex pheromone precursor substances by feeding on daciniphilous orchid flowers that release ME (Nishida and Tan, 2016; Tan et al., 2002, 2006, 2014). Variations in floral synomone components among these orchids would directly influence the sex pheromone composition, and thereby, the females' response to males scented with the 'orchid fragrance'. Thus, another objective of this article is to investigate the fate and accumulation of male rectal gland components in two RK-sensitive fruit fly species after feeding on the synomonal components.

\section{Methods and Materials}

\subsection{Plant and Flower Sampling}

Both $B u$. macranthum and Bu. praetervisum plants were initially collected from four rainforest locations in three Southeast Asian countries by different collectors (see Acknowledgements). They 
were later cultivated ex situ in a private nursery on the fringe of a forest in Penang, Malaysia. $B u$. praetervisum is often misidentified as $B u$. macranthum due to its morphological similarity, but the former is differentiated from the latter by the presence of a small triangular tooth on the column (otherwise stated, it refers specifically to the gynostemium of an orchid flower) wall below each stelidium, and the lip (lateral view) is straight proximally with a hook-like tip (Vermeulen, 2002). The parts of the orchid flowers that are involved in attracting and entrapping a fly during pollination are petals, medial and lateral sepals, lip and column (Fig. 2A). For chemical analysis of the floral scents, freshly bloomed flowers (wrapped in fine netting and prevented from insect visitation) were sampled in the morning within three hours of blooming by cutting the peduncle. In order to obtain the values of floral chemical concentrations (amount per fresh mass, in ppm), the whole flower, or each different floral part, was weighed individually and immersed immediately in redistilled ethanol contained in a screw-capped glass vial. The flower specimens were then subjected to chemical and DNA analyses. Table S1 summarizes the details of plant origin and sampling dates.

\subsection{Observation of Pollination}

Field observations of orchid pollination were conducted in a lowland habitat for various Dacini fruit flies at Tanjong Bungah, Penang, Malaysia. The processes of pollinia removal and deposition during pollination were video-recorded to analyze the movements of both pollinator flies and the mechanical function of floral parts. Fruit fly species visiting newly bloomed $\mathrm{Bu}$. macranthum and $\mathrm{Bu}$. praetervisum flowers, from 08:00 to 10:00 h (for pollinia removal by an attracted fly - until 13:00 h), of different varieties (1-5 plants each) of both Bu. macranthum and Bu. praetervisum were captured and morphologically identified to the species level. Due to irregularity of obtaining plant varieties and flowering events, these observations were conducted for 10-20 solitary flowers per chemotype (except for chemotype 5 - see Result section) from year 2003 to 2015.

\subsection{Floral Scent Analysis}

For quantitative analysis of volatiles, five different floral parts (petals, medial and lateral sepals, lip and column) were carefully removed from a freshly bloomed flower (unexposed to fruit flies) and each weighed before being immersed in ethanol in separate glass vials. For extraction, variable volumes of ethanol were used to submerge each sample depending on the size of flower or floral part, so that the lure chemicals are efficiently extracted from the individual fresh floral parts to minimize any possible effect of enzymatic degradation. Subsequently, the solvent volumes were readjusted with pure ethanol to a standardized volume. Thereafter, a precisely measured portion of the solution was subjected to the GC-quantifications with an internal standard 1-pentadecanol (Aldrich Chem. Ltd., USA). For low-concentration samples, an aliquot of each extract was concentrated in vacuo (approx. $20 \mathrm{~mm} \mathrm{Hg}, \sim 35^{\circ} \mathrm{C}$ ) and extracted with $5 \%$ ethyl acetate in hexane and saturated $\mathrm{NaCl}$. 

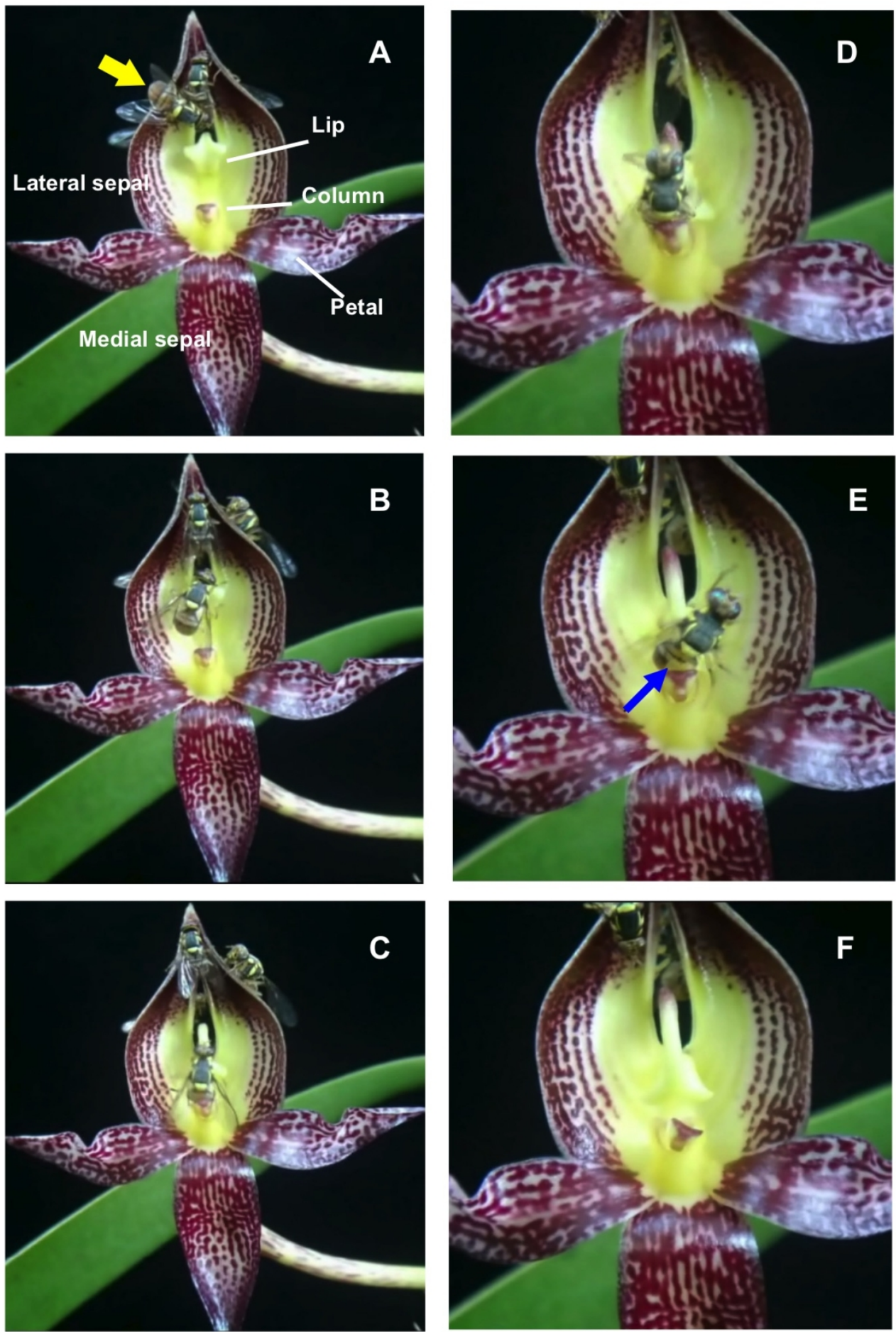

Fig. 2. The process of trapping a fruit fly during pollination: A) A flower of Bulbophyllum macranthum (Philippines-chemotype) visited by 4 Bactrocera dorsalis males on the lateral sepals. A fly (yellow arrow) is feeding on the slippery surface of a lateral sepal. B) While licking, the fly slips down and clings onto the hinged and spring-loaded lip. C) Lip suddenly tilts towards the column due to an imbalance caused by the fly's weight. D) The fly is catapulted backwards abdomen first into the column, where the fly touches the sticky viscidium. To free itself, it wriggles and struggles intermittently. E) The fly has removed the package of four pollinia stuck to the fly's abdominal dorsum (blue arrow) and F) The fly departed. 
The organic layer was dried over anhydrous $\mathrm{Na}_{2} \mathrm{SO}_{4}$ and concentrated carefully under a light nitrogen stream for GC quantification and GC-MS analyses. The amounts and concentrations of the floral volatiles in the individual parts were examined in each flower by the same extraction procedure as above. GC-MS analyses for the floral volatile components were conducted using either an HP 5989B mass spectrometer coupled with an HP 5890 series II plus gas chromatograph (Hewlett Packard, USA) or an Agilent 5975 mass spectrometer coupled with an Agilent $6890 \mathrm{~N}$ gas chromatograph (Agilent Technologies, USA) [in both cases with an HP-5MS capillary column, 5\% phenyl methyl siloxane (30 $\mathrm{m} \times 0.25 \mathrm{~mm}, 0.25 \mu \mathrm{m}$ film thickness), programmed from $60^{\circ}$ (2 min holding) to $290^{\circ} \mathrm{C}$ at a rate of $10^{\circ} \mathrm{C} / \mathrm{min}$, total ion monitor]. GC quantification of volatile chemicals was performed either on an HP 4890A gas chromatograph (Hewlett Packard) [HP-1MS capillary column, $15 \mathrm{~m}$ x $0.25 \mathrm{~mm}, 0.25 \mu \mathrm{m}$ film thickness] or an HP 5890 II Plus gas chromatograph (Hewlett Packard) [HP-5MS capillary column, $30 \mathrm{~m} \times 0.25 \mathrm{~mm}, 0.25 \mu \mathrm{m}$ film thickness] with a flame ionization detector.

\subsection{Rectal Gland Analysis}

Laboratory raised sexually mature virgin males of Z. cucurbitae and Z. tau (24 - 30 days after adult eclosion) were individually allowed to feed on $5 \mu \mathrm{g}$ of synthetic RK (purity $>98 \%$, Tokyo Chemical Industries Co. Ltd., Japan) or ZN (purity $>99 \%$, Tan and Nishida, 2000) for 30 min between 10:00 to 11:00 h. Both chemicals were diluted in redistilled grade ethanol and offered as a thin film on a glass slide in a petri dish. The lure-fed flies were then kept in a screen cage with adult food (sugaryeast hydrolysate mixture in a 3:1 ratio) and water ad libitum. Upon several minutes of light cold immobilization at $4^{\circ} \mathrm{C}$, their rectal glands were dissected from the males at $6 \mathrm{~h}, 1,3$ or 7 days after feeding on either RK or ZN. Unfed males from the same cohort were dissected at the same time intervals and used as parallel controls ( $n=5$ per treatment). Glands were individually soaked in $250 \mu 1$ of redistilled grade ethanol and kept at $-20^{\circ} \mathrm{C}$ until further chemical analysis. GC-quantification was performed for individual rectal gland extract after adding 1-pentadecanol as an internal standard under the same GC conditions as described for the floral scent analysis above.

\subsection{Phylogenetic Analysis}

Total DNA was prepared from individual flowers of each Bulbophyllum species and chemotype using DNeasy Plant Mini Kit (Qiagen, Crawley, UK). PCR amplifications were performed for the two non-coding regions and three fragments of $t r n \mathrm{~L}$ and $t r n \mathrm{~F}$ genes of chloroplast DNA using universal primers, c and f (Taberlet et al., 1991). PCR conditions were: $94^{\circ} \mathrm{C}$ for $2 \mathrm{~min} ; 35$ cycles of $94^{\circ} \mathrm{C}$ for 1 $\min , 55^{\circ} \mathrm{C}$ for $1 \mathrm{~min}, 72^{\circ} \mathrm{C}$ for $2 \mathrm{~min}$, and $72^{\circ} \mathrm{C}$ for $2 \mathrm{~min}$. The PCR products were cloned into pGEMT Easy vector (Promega ${ }^{\circledR}$, WI, USA) and sequences of the clones were determined by using T7 and SP6. The DNA sequence data have been deposited in the DDBJ/EMBL-Bank/GenBank as listed in Table S1. In addition to $B u$. macranthum and $B u$. praetervisum chemotypes, a specimen of $B u$. 
vinaceum (sample code V12, collected Feb 18, 2004; origin, Sabah, Malaysia) was also included for comparison.

Sequence alignment was performed by using the software Clustal W 2.1. The phylogenetic tree was generated by aligning the 1042 to 1067 bp nucleotide sequences of amplified fragments by the PCR using the corresponding sequence of Dendrobium officinale Kimura \& Migo (KJ862886) as an outgroup. The maximum likelihood method was conducted by MEGA 5 (Tamura et al., 2011) under the General Time Reversible model with among-site rate heterogeneity according to a Gamma distributed with Invariant sites $(\mathrm{G}+\mathrm{I})$.

\section{Results}

\subsection{Observation of Pollination}

The process of pollinia removal of a $B u$. macranthum flower (Philippines-chemotype) by a $B a$. dorsalis male is illustrated in Fig 2. Anthesis usually started $0.5-1 \mathrm{~h}$ before dawn (breaks at ca 07:00 h) and concluded by 08:30 h. When the fly visitor was licking the surface of lateral sepals (Fig. 2A), it suddenly slipped (Fig. 2B) from the slippery surface of the upright lateral sepals on to the hinged lip which then tipped it backwards abdomen first into the column cavity (Figs. 2C and D). In this manner, the fly touched the sticky viscidium via its abdomen and got stuck to the column. Since the pollinia were covered by the anther cap and still attached to the column, the fly could not easily free itself until the pollinia were loosened from the anther cap with vigorous wing-buzzing (Fig. 2E). After much struggling, the fly was eventually freed with the pollinia firmly stuck to its abdomen (Fig. 2F). The process of pollinia removal would normally take about $30 \mathrm{~min}$. Nonetheless, if stuck to the column longer than $2 \mathrm{~h}$, the fly would die from fatigue and dehydration as was observed in a dozen occasions. The floral architecture and the process of pollination in Bu. praetervisum (Fig. 1B) are basically the same as those in Bu. macranthum (Fig. 2). The last phase of pollination (i.e., deposition of pollinia from one flower on to the stigma of another, a rarely observed phenomenon) in Bu. praetervisum by a $B a$. albistrigata male and a $Z$. caudatus male was also successfully video-recorded [Suppl. video 1: Pollinia deposition on to the stigma by $Z$. caudatus].

\subsection{Fruit Fly Species Attracted to the Flower}

Dacini males of both ME-sensitive species (Ba. carambolae, Ba. dorsalis and Ba. umbrosa) and RK-sensitive species (Ba. albistrigata, Ba. melastomatos, Z. caudatus, Z. cucurbitae and Z. tau) were observed to visit $B u$. macranthum flowers, one from Langkawi, Malaysia (Fig. 1A) and another from Chiang Mai, Thailand (chemotype 1; Table 1) (see Fig. 3 for chemotype classification by floral synomone constituents). However, Bu. macranthum originating from Laguna, Philippines (chemotype 
2; Fig. 2) attracted only ME-sensitive species, suggesting some differences in chemical compositions of attractants among the flowers. For Bu. praetervisum, both chemotype 3 and chemotype 4 flowers of $B u$. praetervisum attracted the RK-sensitive species as listed above. More Z. cucurbitae males visited flowers of chemotype 3 than chemotype 4 in the field observation in Penang, Malaysia.

Table 1. Bactrocera and Zeugodacus fruit fly species visiting flowers of different local chemotypes* of Bulbophyllum macranthum and Bu. praetervisum varieties.

Bu. macranthum

Fruit fly species
MY

Chemotype 1
$\mathrm{TH}$

Chemotype 1
PH

Chemotype 2
Bu. praetervisum var.

MY

MY

Chemotype 3 Chemotype 4

\section{RK-sensitive}

Ba. albistrigata

Z. caudatus

Z. cucurbitae

Z. tau
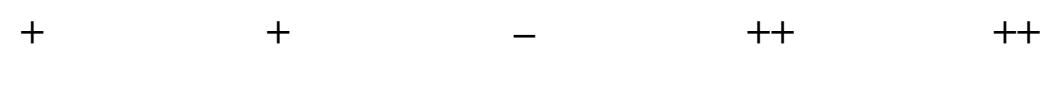

ME-sensitive

Ba. carambolae

Ba. dorsalis

Ba. umbrosa

+
+
+

+
+
+

$+$

$+$

$+$

$++$

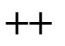

$+$

$+$

*Origins of local chemotypes: MY = Malaysia; $\mathrm{TH}=$ Thailand and $\mathrm{PH}=$ Philippines; no data for Chemotype 5 flowers

- : no fly attracted, + : occasional (1-2 flies observed on $<50 \%$ flowers), ++ : regular (1-3 flies on every flower observed), $+++:$ many flies ( $>10$ flies on every flower)

\subsection{Floral Scent Analysis}

The major volatile components detected in different floral chemotypes differ between and within species. The major floral component of $B u$. macranthum chemotype 1 from Malaysia and Thailand was identified as ZN (Figs. 3 and S1). In addition, most of the samples contained a small percentage of zingerol (4-(4-hydroxy-3-methoxyphenyl)-2-butanol) (ZL) as a minor component often accompanied, in trace amounts, RK and eugenol (2-methoxy-4-(2-propenyl)phenol) (EU). In contrast, $B u$. macranthum chemotype 2 from the Philippines lacked ZN entirely, but ME was found as the most 
prominent component with a small amount of EU (Figs. 3 and S1). (E)-Methyl isoeugenol ((E)-1,2dimethoxy-4-(1-propenyl)benzene) was also detected in some of the samples of chemotype 2 as a minor component (retention index: 1500 on an HP-5MS column) (Fig. S1).

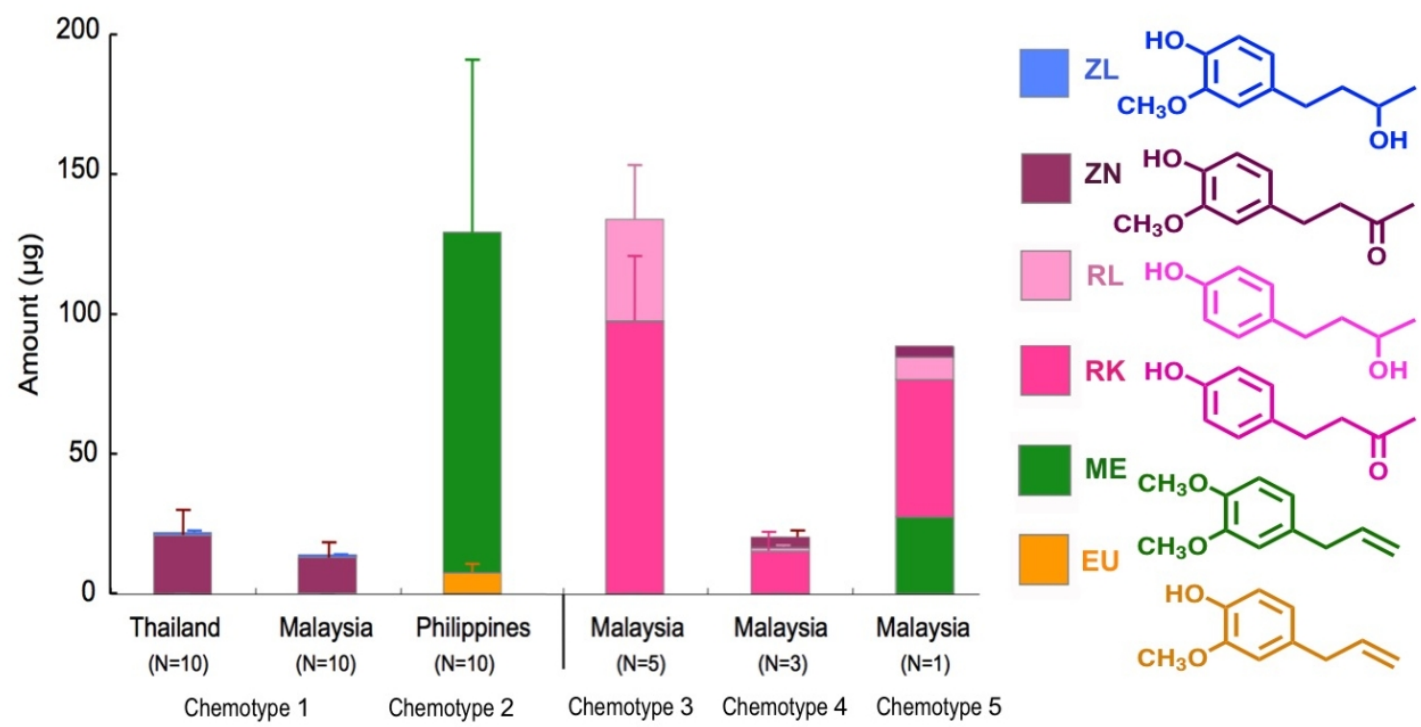

Bu. macranthum

Bu. praetervisum

Fig. 3. Amounts (mean \pm S.D.; $\mu$ g per flower) of volatiles of different local chemotypes of Bulbophyllum macranthum and Bu. praetervisum . EU: eugenol, ME: methyl eugenol, RK: raspberry ketone, RL: rhododendrol, ZN: zingerone, ZL: zingerol.

Most of the whole flower samples of Bu. praetervisum (all originated from Sabah, Malaysia) contained RK as the major component. This was accompanied by several other compounds, and the different variants were tentatively classified as different chemotypes, namely chemotype 3,4 and 5, respectively (Figs. 3 and S1). Chemotype 3 possessed a mixture of RK and rhododendrol (4-(4hydroxyphenyl)-2-butanol) (RL), while chemotype 4 contained RK, RL and ZN. Notably, one of the $B u$. praetervisum specimens from a different source in Sabah - chemotype 5 (all attempts to get more flowers over the past 15 years had failed) contained ME as the second major constituent.

Flowers of Bu. macranthum chemotype 1 from Malaysia and Thailand had similar amounts of ZN and ZL (Fig. 3). The mean amount of ME in the Bu. macranthum Philippines-chemotype was approximately $100 \mu \mathrm{g} /$ flower, although the quantities varied among the flowers (45-275 $\mu \mathrm{g}$ /flower). In the $B u$. praetervisum flowers, RK was the most abundant constituent in all chemotypes (chemotypes 3 , 4 and 5) (Fig. 3). Mean amount of RK in chemotype 3 was as high as $100 \mu \mathrm{g} /$ flower accompanied by substantial quantities of RL. While chemotype 3 lacked ZN, chemotypes 4 and 5 contained ZN. Among all $\mathrm{Bu}$. praetervisum specimens examined, only chemotype 5 exhibited a blend of 
phenylpropanoids (EU and ME) and phenylbutanoids (RK, RL and ZN), the sum of which reached nearly $100 \mu \mathrm{g} /$ flower.

Distribution of attractants in floral parts was examined for each chemotype. Since $B u$. macranthum from Malaysia and Thailand gave similar chemical profiles (chemotype 1) and amounts, they were combined to obtain mean amounts and mean concentrations in each floral part. For chemotype 1, ZN was found in all parts, while ZL was present only in the lateral sepals (Fig. 4). The lip is the lightest in weight, yet the relative concentration of $\mathrm{ZN}$ is the highest. None of the volatiles was found in the column. Although the composition of volatiles in chemotype 2 (Philippines) differed greatly from those Malaysia- and Thailand-chemotypes (chemotype 1), the proportions of volatiles in each floral part were similar in that the concentration of ME in the lip was relatively high. The columns also contained small amounts of ME in the Philippines-chemotype.

\section{Bulbophyllum macranthum}
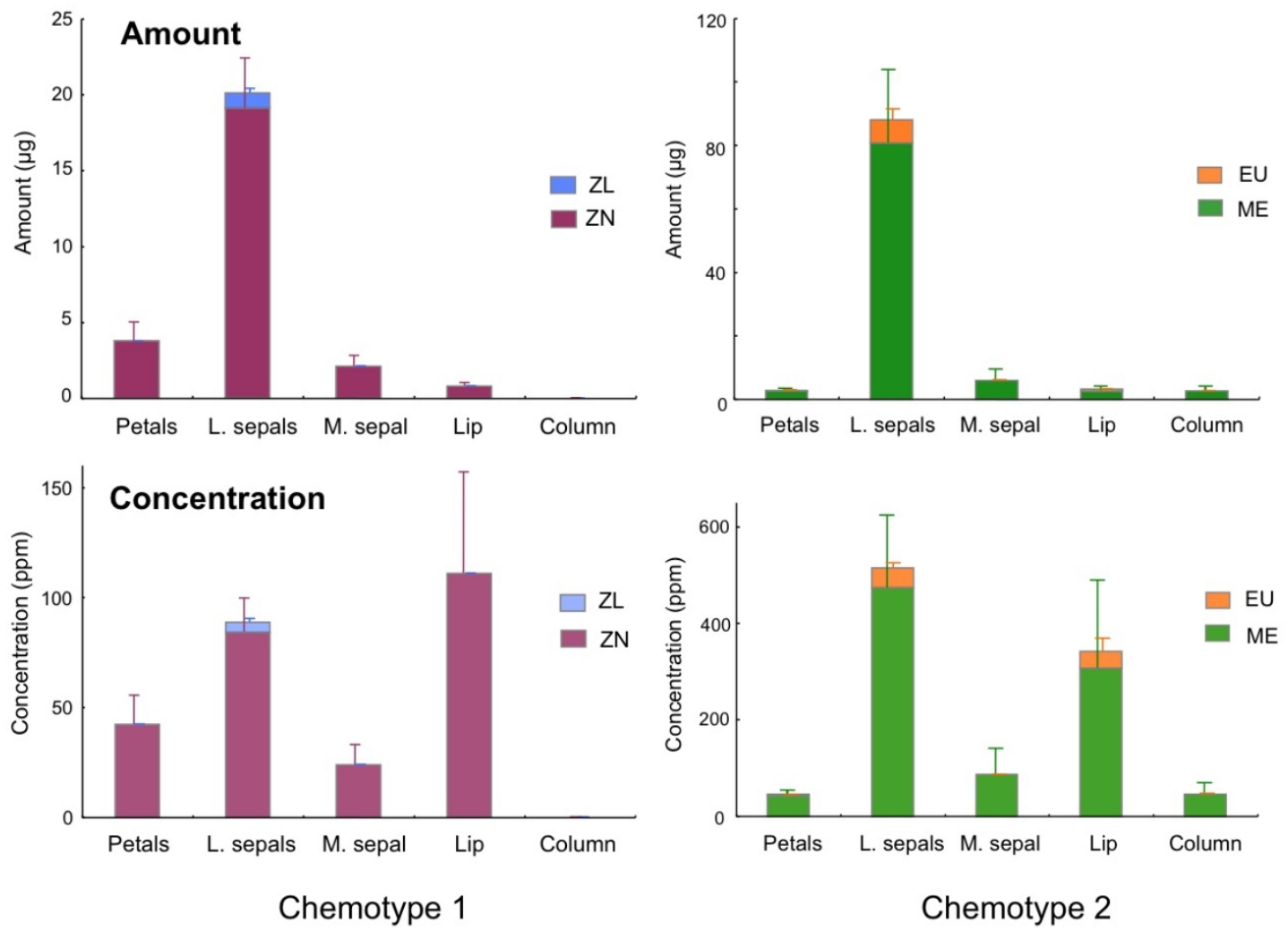

Fig. 4. Amounts (mean \pm S.D., $\mu$ g per flower) (upper) and concentrations (mean \pm S.D., amount per fresh mass in ppm) (bottom) of volatiles in each floral part of Bulbophyllum macranthum:

Chemotype 1 (left): Thailand and Malaysia specimens combined $(n=7$, mean \pm S.D.);

Chemotype 2 (right): Philippine specimens $(\mathrm{n}=4$, mean \pm S.D.). All samples were collected and extracted without being exposed to fruit flies. ZN: zingerone, ZL: zingerol, EU: eugenol, ME: methyl eugenol. 
Among the three chemotypes of $B u$. praetervisum, the amounts of attractants were consistently highest in the lateral sepals (Fig. 5). Interestingly, the relative concentration in the lips appeared low in chemotypes 3 and 4 when compared with that of Bu. macranthum chemotype 1 (Malaysia and Thailand) (Fig. 4). However, in chemotype 5, the concentration of ME in the lip was conspicuously high in relative proportion, and the column also possessed ME in a significant quantity. ZN, which was absent from chemotype 3, was present only in the lateral sepals in chemotypes 4 and 5, respectively.

\section{Bulbophyllum praetervisum}
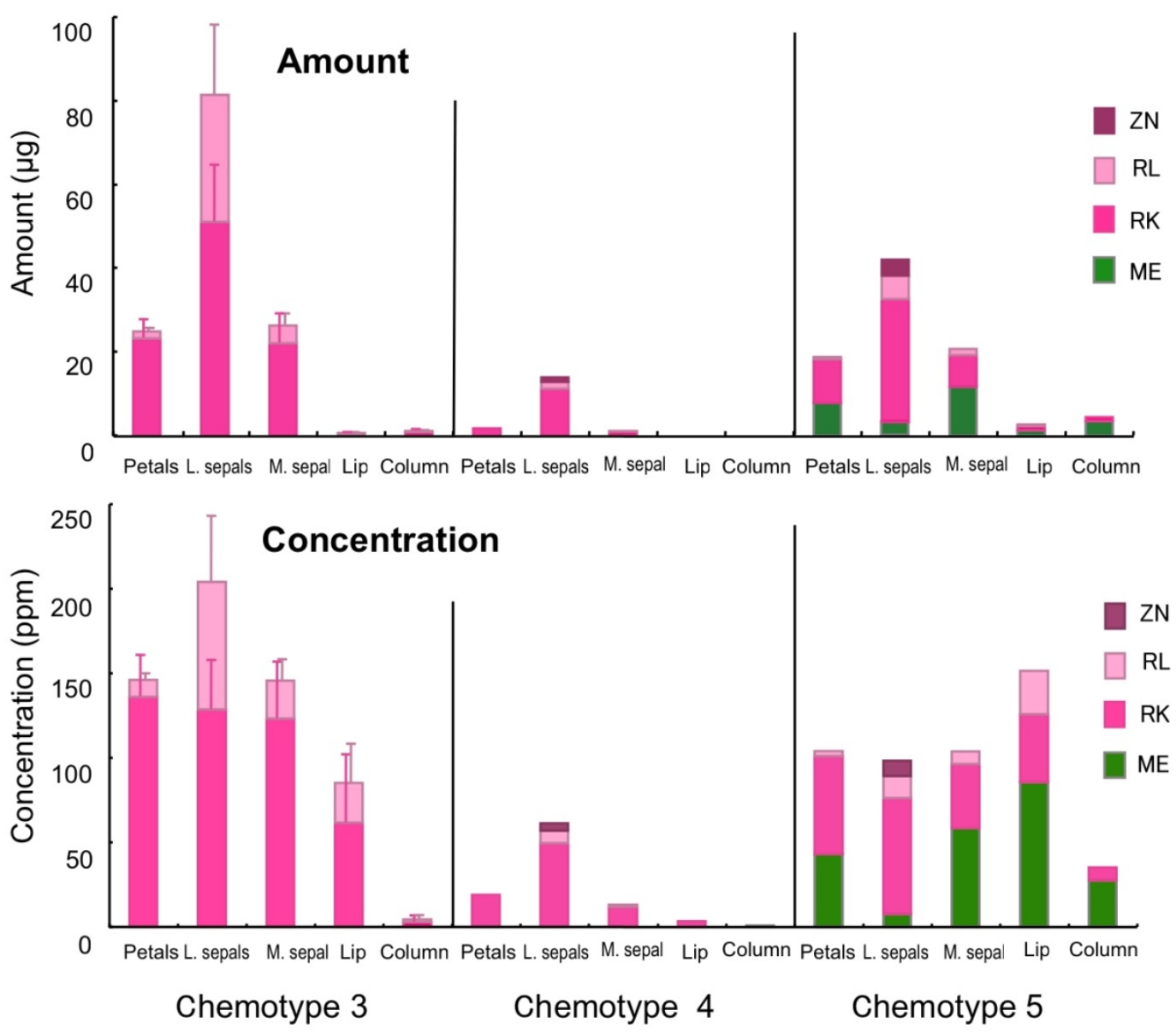

Fig. 5. Amounts (mean \pm S.D., $\mu$ g per flower) (upper) and concentrations (mean \pm S.D., amount per fresh mass in ppm) (bottom) of volatiles in each floral part of Bulbophyllum praetervisum originated from Borneo, Malaysia [Chemotype $3(n=5)$, Chemotype $4(n=1)$ and Chemotype $5(n=1)]$. All samples were collected and extracted without being exposed to fruit flies. ME: methyl eugenol, RK: raspberry ketone, RL: rhododendrol, $\mathrm{ZN}$ : zingerone. 


\subsection{Rectal Gland Analysis}

Males of Z. cucurbitae and Z. tau that fed on synthetic RK and ZN effectively accumulated the respective compounds in the rectal glands from $6 \mathrm{~h}$ after feeding (Fig. 6). In each case, the corresponding alcohols, RL or ZL, were also present in small quantities (mostly less than $5 \%$ of the total amount). The total quantities of RK and ZN in Z. cucurbitae were similar, approximately 2-2.5 $\mu \mathrm{g} /$ gland between 1- and 7-day post-treatment. The amount sequestered in the gland corresponded to nearly half of the amount offered to the fly. However, in Z. tau males, for the same amount of attractants offered, the accumulated RK was less than $1 \mu \mathrm{g} / \mathrm{gland}$, whereas $\mathrm{ZN}$ was present in trace quantities. Neither RK nor ZN was detected in the control males.
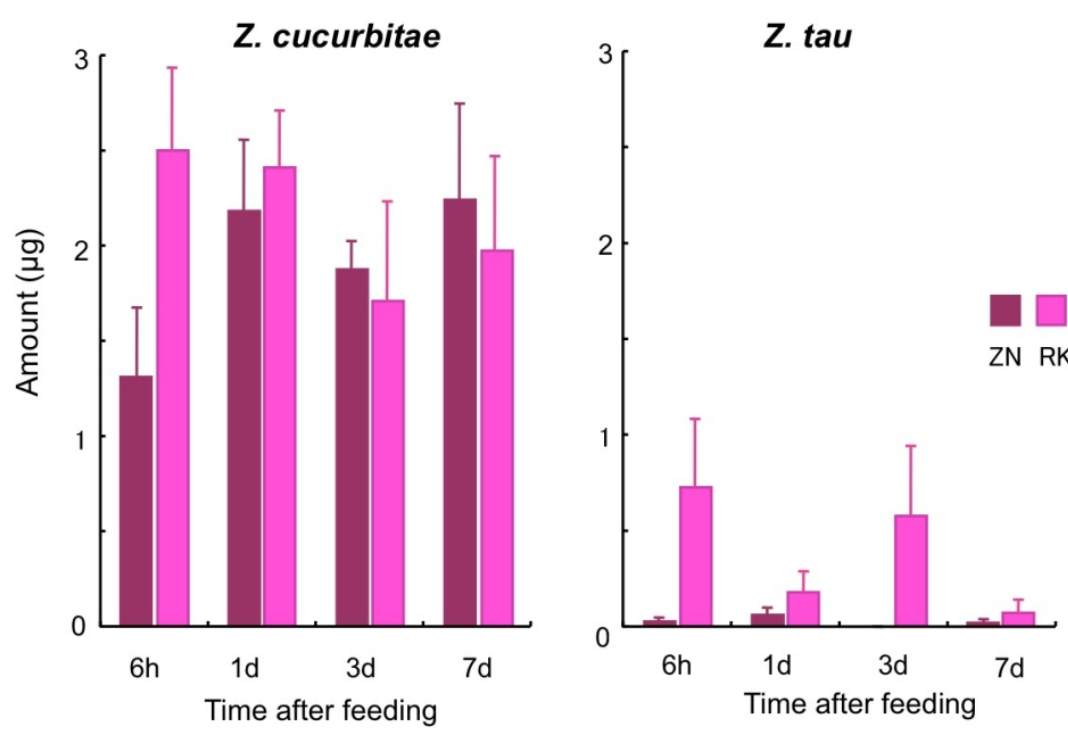

Fig. 6. Amounts (mean \pm S.E., $\mu \mathrm{g} / \mathrm{gland}$ ) of zingerone $(\mathrm{ZN})$ and raspberry ketone $(\mathrm{RK})$ accumulated in male rectal glands of Zeugodacus cucurbitae, and Z. tau at $6 \mathrm{~h}, 1 \mathrm{~d}, 3 \mathrm{~d}$ and $7 \mathrm{~d}$ after initial feeding of either $\mathrm{ZN}$ or RK $(\mathrm{n}=5)$.

\subsection{Phylogenetic Analysis}

The phylogenetic analysis showed that the two chemotypes of Bu. macranthum and the three chemotypes of $B u$. praetervisum converged on the same single lineage, even though their floral chemical profiles are distinctly different (Fig. 7). Only the lineage of Bu. macranthum chemotype 2 from Philippines was slightly but confidently distinct from the single lineage comprising the other $B u$. macranthum and Bu. praetervisum chemotypes. It should be noted that the chemotype 2 showed the unique chemical profile in which ME was the major component clearly distinct from the other chemotypes of Bu. macranthum and Bu. praetervisum. Furthermore, the lineage of Bu. macranthum 
and $B u$. praetervisum chemotypes is clearly apart from the lineage of $B u$. vinaceum which is another daciniphilous orchid producing a large array of phenylpropanoids including EU and ME.

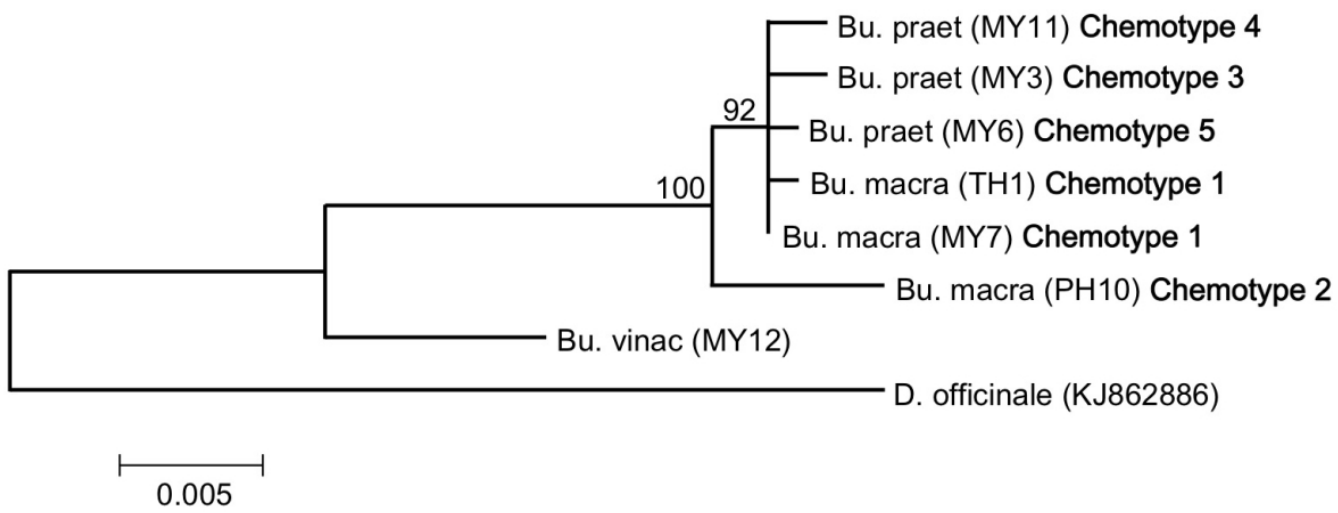

Fig. 7. Phylogenetic relationships of daciniphilous orchids in the genus Bulbophyllum resulting from the maximum likelihood method. The scale bar indicates the evolutionary distance between the groups. The $\operatorname{trn} \mathrm{L}$ and $\operatorname{trn} \mathrm{F}$ genes of chloroplast DNA were used for construction of the phylogenetic tree. Bu. macra $=B u$. macranthum; $\mathrm{Bu}$. praet $=B u$. praetervisum $; \mathrm{Bu}$. vinac $=B u$. vinaceum and $\mathrm{D}$. officinale = Dendrobium officinale (outgroup). $\mathrm{MY}=$ Malaysia-chemotype; $\mathrm{TH}=$ Thailand-chemotype; $\mathrm{PH}=$ Philippines-chemotype. See details of orchid specimens and accession numbers in Table S1.

\section{Discussion}

The floral volatile components from both Bu. macranthum and Bu. praetervisum differ drastically from locality to locality within a single orchid species, thereby, attracting different fruit fly fauna belonging to ME- and/or RK-sensitive species as well as of different genera as summarized in Fig. S2. According to our phylogenetic analyses based on chloroplast DNA sequences, the two sibling species are in the same lineage regardless of different floral synomone biochemistry to produce either phenylpropanoids or phenylbutanoids except the Philippines-chemotype of Bu. macranthum (Fig. 7). The Philippines-chemotype of Bu. macranthum is slightly separated from the other $B u$. macranthum and $B u$. praetervisum chemotypes, suggesting a possibility that it is a different species from $B u$. macranthum irrespective of taxonomic features based solely on floral morphology. While these findings partly contradict the current taxonomic status of the two species and that of the Philippineschemotype, we analyzed the phylogenetic relationships based only on chloroplast DNA sequences using the universal primers, due to the limited genetic information of the closely related orchid species. Therefore, further in-depth evaluations such as sequence analyses of nuclear genes and microsatelites, are warranted to ascertain the actual species delimitation of these orchid taxa and to examine if they are arising from populations of a highly polymorphic species. 
Among over 500 Dacini species found in central Southeast Asia, thus far in published literature, there is no species known to respond to both ME and CL/RK. Besides ME-, RK- and ZN-sensitive species, several other phenylpropanoids that are structurally related to ME, such as isoeugenol and methyl isoeugenol, have recently been reported to be specific attractants for certain endemic fruit fly species in the Australian and Papua New Guinean regions (Royer et al., 2018a,b). The pollination syndromes between various Dacini fruit fly species and Bulbophyllum orchids may have advanced adaptively through diffuse coevolution (Lunau, 2004). Nonetheless, it is uncertain whether the males' strong affinity to ME, RK or ZN evolved before the establishment of mutualistic interactions between Dacini fruit flies and fruit fly orchids involving a pre-existing bias of chemosensory ability in the pollinators (Schiestl and Dötterl, 2012). According to the phylogenetic analysis of the fruit fly species in the subfamily Dacinae based on mitochondrial DNA analysis, CL/RK-response was suggested to be plesiomorphic to ME-response, and the latter has evolved independently within the Bactrocera and Zeugodacus groups (Smith et al., 2003). However, a recent molecular phylogenetic analysis has shown that there were no apparent correlations between phylogenetic relationships of the dacini fruit flies and their responsiveness to attractants (Krosch et al., 2012). Therefore, the utilization of floral scents as their pheromone sources may have occurred multiple times in the mutualistic interactions between Dacini fruit flies and fruit fly orchids. The molecular basis of chemosensory system in the pollinators and the biosynthetic pathways of phenylpropanoids/phenylbutanoids in the orchids may elucidate the history of those mutualistic interactions via floral synomones as further discussed below.

Floral scent-mediated plant speciation would take place through pollinator shifts (Okamoto et al., 2015; Peter and Johnson, 2014), although there may be various other factors involved in the pollination syndromes (Ellis and Johnson, 2009; Hoffmeister et al., 2016). Floral chemical changes from sweet-smelling to foul-smelling (or vice versa) have caused the drastic pollinator shift between insect orders or even to vertebrates (Schiestl and Johnson, 2013; Shuttleworth and Johnson, 2009). In the case of Bu. macranthum and Bu. praetervisum and their intraspecific chemotypes, however, the floral biochemical change is limited within phenylpropanoids and phenylbutanoids, and thus, pollinator switching is restricted within the Bactrocera and Zeugodacus genera of the Dacini fruit flies. The biosynthetic pathways of phenylpropanoids/phenylbutanoids have been extensively studied at the genomic level in higher plants (Vogt, 2010). While ME is biosynthesized from phenylalanine/tyrosine via feruloyl CoA to coniferyl alcohol followed by reduction and $O$ transmethylation (Renu et al., 2014), RK and ZN are synthesized by decarboxylative condensation of 4-coumaroyl CoA and malonyl-CoA with a benzalacetone synthase followed by reduction of the butenyl moiety with a NADPH-dependent reductase to form the phenylbutanoid skeletal structures (Koeduka et al., 2011). In particular, Bu. praetervisum chemotype 5 likely furnishes all the necessary enzymes to produce both the phenylpropanoids and phenylbutanoids as the flower contained both classes of analogs including ME, RK, RL and ZN. While both Malaysia- and Thailand-chemotypes of 
$B u$. macranthum (chemotype 1) possess small quantities of phenylpropanoid EU in common, chemotype 2 from the Philippines entirely lacks phenylbutanoid components, which suggests a possible suppression of the phenylbutanoid pathway and an expression of 4-O-methyltransferase to produce ME (Gang et al., 2002). The elucidation of biosynthetic pathways and gene-expression regulation mechanisms between the phenylpropanoids and phenylbutanoids at the molecular level will certainly provide an insight into the evolutionary processes among these closely related Bulbophyllum sibling species; and certainly warranted future investigations.

Interestingly, in these Bulbophyllum orchids, each of the major floral volatile was always accompanied by its corresponding analogous compound as a minor component in a pairwise manner: ZN/ZL, RK/RL and ME/EU (Fig. 3). In Bu. macranthum, the minor component ZL was found exclusively in the lateral sepals of chemotype 1, whereas EU was found selectively in the lateral sepals and lip of chemotype 2. A similar relationship in the distribution of minor components (RL and ZN) exists among the 3 chemotypes of Bu. praetervisum. Lateral sepals are the floral parts where the flies most frequently spend time probing and ingesting synomonal components prior to the pollination event as described below. Although these minor components alone may not induce strong lure-activity in males of $B a$. dorsalis and $Z$. cucurbitae, the pairwise formulation (ZN/ZL, RK/RL and ME/EU) found in lateral sepals may effectively enhance phagostimulant activity in the pollinator fruit fly species. According to our GC-MS analysis, a number of samples of both Bu. macranthum and $B u$. praetervisum flowers possess phenylacetaldehyde (GCMS: $R t=7.95 \mathrm{~min}$, HP-5), a phenylethanoid known as a general floral fragrance (Huber et al., 2005), in varying quantity, which may also assist in the orientation of pollinator flies from a distance toward the chemical source.

The floral architecture and dynamic lip mechanism to temporarily trap fruit flies in $B u$. macranthum and $B u$. praetervisum are very similar, with a subtle difference in the shape of the lip (Vermeulen, 2002). Male Dacini flies most frequently land on the lateral sepals in both the Bulbophyllum species. The spatio-distribution of floral synomone on a blooming fruit fly orchid flower appears to guide the fly to feed on the slippery surface of the lateral sepals towards the 'springloaded' hinged lip that contains the highest concentration of attractant components amongst the various floral parts. This forces the fly to fall on its backside into the column cavity. This strategy effectively brings the fly into the right position for its abdominal dorsum to receive the pollinia, and then, to unload onto the stigma of another flower with a high precision. Thus, the basic mechanism to temporarily trap a fly appears the same for the two Bulbophyllum sibling species. The position of the pollinia attached dorsally to the fly's abdomen from Bu. macranthum and Bu. praetervisum is very precise, and distinctly different from other daciniphilous orchid species (e.g. Bu. patens, Bu. apertum, Bu. cheiri and Bu. vinaceum) (Nishida et al., 2004; Tan and Nishida, 2000, 2005, 2007; Tan et al., $2002,2006)$. In the latter cases, the pollinator flies always receive pollinia on the thoracic dorsum due to highly dynamic lip mechanisms, which are entirely different from the pitfall column gimmick in $B u$. 
macranthum and $\mathrm{Bu}$. praetervisum. Clarke et al. (2002) conducted a massive survey on orchid visitation by Bactrocera/Zeugodacus fruit fly species in Papua New Guinea, and detected a number of fruit flies bearing pollinaria on either the thoracic or abdominal dorsum. Interestingly, most of the flies captured by ME traps bore pollinaria on the thorax, whereas the CL captured flies carried pollinaria on the abdomen. The position where the removed pollinarium is stuck - either the fly's thoracic or abdominal dorsum may indicate which group of daciniphilous Bulbophyllum species the pollinarium belongs to. Nevertheless, for Bulbophyllum species identification via pollinia/pollinarium found on a fly, we still await the results from morphological and DNA analyses of Bulbophyllum pollinaria.

The floral volatiles are recognized as 'floral synomone' to mutually benefit the reproductive systems of both the flowers and fruit fly pollinators (Nishida and Tan, 2016; Tan and Nishida, 2000). Incorporation of phenylpropanoid or phenylbutanoid floral volatiles into the sex pheromone repertoire of Bactrocera/Zeugodacus species appears to have evolved in the context of sexual selection, particularly female preference for males scented with the flower-originated pheromone chemicals (Kumaran et al., 2013; Nishida et al., 1997; Shelly, 2010; Wee et al., 2007, 2018). The quality and quantity of floral synomone supplied by orchids may indirectly affect the female's response toward the male's pheromone-smoke emission. Nevertheless, a female's preference to certain floweroriginated male pheromone precursors/components may provide a feedback mechanism pertaining to the composition of floral volatiles through interactions with pollinator male flies. Thus, the composition of floral volatiles would reciprocally influence the fates of both the orchids and the fruit flies in two phases - firstly, response to floral synomone by a male; and secondly, response to male pheromone by a female - through the direct reproductive benefits for both interacting organisms and/or indirect benefit to their offspring (Kumaran and Clarke, 2014).

Besides, the sequestered phenylpropanoids were shown to act as a potential allomone to deter feeding of predatory animals such as birds, lizards and spiders in Ba. dorsalis (Nishida and Fukami, 1980; Tan and Nishida, 1998; Wee and Tan, 2001) that would ensure the protection and security of the pollinator fruit flies to deliver pollinaria. Therefore, similar to the case of sex pheromone above, the quality and quantity of floral synomone offered to male flies may be crucial for successful pollination. This would invoke a concomitant operation of both the sexual selection (via sex pheromone) and natural selection (via allomone) mediated by floral attractants (via synomone).

The composition of the pollinator communities (pollinator spectrum) is apparently reflected by the species' affinity to specific floral synomones. ZN conforms to a hybrid structure of ME and RK. This is a probable reason as to why both ME- and RK-sensitive species visit flowers containing ZN as a major floral component (Tan and Nishida, 2000, 2007). Such duality may have enabled the flowers to secure a wider range of pollinator species and/or higher success rate of pollination under a certain spatio-temporal milieu in a rain forest possibly during a shortage of certain pollinator flies. From the plants' point of view, the fairly diverse array of potential pollinators among Bactrocera and 
Zeugodacus species may provide an adequate pool of potential pollinators, which can be further modified reciprocally by fine-tuning the floral ingredients to closely match the local fly fauna. Nonetheless, the male flies can obtain the pheromone/allomone materials or precursors from other plant sources. As the phenylpropanoids/phenylbutanoids attractants are distributed widely in nature (Tan and Nishida, 2012, Tan et al., 2014), the attractants may cause a possible asymmetrical mutualistic relationship with unbalanced reciprocal effects (Lunau, 2004). Therefore, the abundance of effective or faithful pollinators in the orchid habitat is a crucial component to ensure successful sexual reproduction. A systematic study of these floral synomones at a population level will provide a key to better understand the coevolutionary radiation between the pollinators and orchids, since both the Dacini fruit flies and $B u$. macranthum have a wide geographical distribution - centered from pantropical Southeast Asia and Oceania regions to surrounding countries including India.

Acknowledgements We thank J.J. Vermeulen, P.T. Ong and V. Yap for providing the various chemotypes of the orchids; K.L. Heong and A. K-W. Hee for obtaining export and import permits, respectively, for the $B u$. macranthum chemotype from Philippines. We are grateful to J.J. Vermeulen and the late P. O'Byrne for identifying and confirming the latter chemotype originally labeled as $B u$. emiliorum. We also thank T.E. Shelly for their critical comments on the manuscript. R. Nishida was partly supported by the Grant-in-Aid for Scientific Research from JSPS (Nos. 19310142 and 23380035) and a Grant-in-Aid for the 21st Century COE Program for Innovative Food and Environmental Studies Pioneered by Entomomimetic Sciences, from the Ministry of Education, Culture, Sports, Science and Technology of Japan. H. Ono and S.L. Wee were partly supported by JSPS KAKENHI Grant Number 26450466 and Ganjaran Penerbitan (GP-K016221), respectively.

\section{Reference}

Ayasse, M., Stökl, J., Francke, W., 2011. Chemical ecology and pollinator-driven speciation in sexually deceptive orchids. Phytochemistry 72, 1667-1677.

Bohman, B., Phillips, R.D., Menz, M.H.M., Berntsson, B.W., Flematti, G.R., Barrow, R.A., Dixon, K.W., Peakall, R., 2014. Discovery of pyrazines as pollinator sex pheromones and orchid semiochemicals: implications for the evolution of sexual deception. New Phytol. 20, 939-952.

Clarke, A.R., Balagawi, S., Clifford, B., Drew, R.A.I., Leblanc, L., Mararuai, A., Mcguire, D., Putulan, D., Sar, S.A., Tenakanai, D., 2002. Evidence of orchid visitation by Bactrocera species (Diptera: Tephritidae) in Papua New Guinea. J. Tropical Ecol. 18, 441-448.

Dobson, H.E.M., 1994. Floral volatiles in insect biology. In: Bernays, E. (Ed.), Insect-Plant Interactions, pp. 4781. CRC Press, Boca Raton, Florida.

Dressler, R.L., 1982. Biology of the orchid bees (Euglossini). Annu. Rev. Ecol. Syst. 13, 373-394.

Ellis, A.G., Johnson, S.D., 2009. The evolution of floral variation without pollinator shifts in Gorteria diffusa (Asteraceae). Am. J. Bot. 96, 793-801. 
Gang, D.R., Lavid, N., Zubieta, C., Chen, F., Beuerle, T., Lewinsohn, E., Noel, J.P., Pichersky, E., 2002. Characterization of phenylpropene $O$-methyltransferases from sweet basil: Facile change of substrate specificity and convergent evolution within a plant $O$-methyltransferase family. Plant Cell 14, 505-519.

Hoffmeister, M., Wittköpper, N., Junker, R.R., 2016. Herbivore-induced changes in flower scent and morphology affect the structure of flower-visitor networks but not plant reproduction. Oikos 125, 12411249.

Huber, F.K., Kaiser, R., Sauter, W., Schiestl, F.P., 2005. Floral scent emission and pollinator attraction in two species of Gymnadenia (Orchidaceae). Oecologia 142, 564-575.

Jasáková, J., Johnson, S.D., Kindlmann, P., 2006. Mechanisms and evolution of deceptive pollination in orchids. Biol. Rev. 81, 219-235.

Johnson, S.D., Edward, T.J., 2000. The structure and function of orchid pollinaria. Plant Syst Evol 222, $243-269$.

Johnson, S.D., Steiner, K.E., 2000. General versus specialization in plant pollination systems. Trends Ecol. Evol. $15,140-143$.

Koeduka, T., Watanabe, B., Suzuki, S., Hiratake, J., Mano, J., Yazaki, K., 2011. Characterization of raspberry ketone/zingerone synthase, catalyzing the alpha, beta-hydrogenation of phenylbutenones in raspberry fruits. Biochem. Biophys. Res. Commum. 412, 104-108.

Krosch, M.N., Schutze, M.K., Armstrong, K.F., Graham, G.C., Yeates, D.K., Clarke, A.R., 2012. A molecular phylogeny for the Tribe Dacini (Diptera: Tephritidae): Systematic and biogeographic implications. 64. 513523.

Kumaran, N., Clarke, A.R., 2014. Indirect effects of phytochemicals on offspring performance of Queensland fruit fly, Bactrocera tryoni (Diptera: Tephritidae). J. Appl. Entomol. 138, 361-367.

Kumaran, N., Balagawi, S., Schutze, M.K., Clarke, A.R., 2013. Evolution of lure response in tephritid fruit flies: phytochemicals as drivers of sexual selection. Anim. Behav. 85, 781-789.

Lunau, K., 2004. Adaptive radiation and coevolution — pollination biology case studies. Org. Divers. Evol. 4, 207-224.

Metcalf, R.L., 1990. Chemical ecology of Dacinae fruit flies (Diptera: Tephritidae). Ann. Entomol. Soc. Am. 83: 1017-1030.

Nilsson, L.A., 1992. Orchid pollination biology. Trends Ecol. Evol. 7, 255-259.

Nishida, R., Fukami, H., 1990. Sequestration of distasteful compounds by some pharmacophagous insects. J. Chem. Ecol. 16, 151-164.

Nishida, R., Tan, K.H., 2016. Search for new fruit fly attractants from plants: a review. pp. $249-262$. Proceedings of the 9 th ISFFEI.

Nishida, R., Tan, K.H., Takahashi, S., Fukami, H., 1990. Volatile components of male rectal glands of the melon fly, Dacus cucurbitae Coquillett (Diptera: Tephritidae). Appl. Entomol. Zool. 25, 105-112.

Nishida, R., Iwahashi, I., Tan, K.H., 1993. Accumulation of Dendrobium (Orchidaceae) flower fragrance in the rectal glands by males of the melon fly, Dacus cucurbitae (Tephritidae). J. Chem. Ecol. 19, 713-722.

Nishida, R., Shelly, T.E., Kaneshiro, K.Y., 1997. Acquisition of female-attracting fragrance from a Hawaiian lei flower, Fagraea berteriana, by males of the oriental fruit fly. J. Chem. Ecol. 23, 2275-2285.

Nishida, R., Tan, K.H., Wee, S.L., Hee, A.K.W., Toong, Y.C., 2004. Phenylpropanoids in the fragrance of the fruit fly orchid, Bulbophyllum cheiri, and their relationship to the pollinator, Bactrocera papayae. Biochem Syst Ecol 32, 245-252.

Nordlund, D.A., Lewis, W.J., 1976. Terminology of chemical releasing stimuli in intraspecific and interspecific interactions. J. Chem. Ecol. 2, 211-220.

Okamoto, T., Okuyama, Y., Goto, R., Tokoro, M., Kato, M., 2015. Parallel chemical switches underlying pollinator isolation in Asian Mitella. J. Evol. Biol. 28, 590-600. 
Ong, P.T., Tan, K.H. 2011. Fly pollination in four Malaysian species of Bulbophyllum (Section Sestochilus) - B. lasianthum, B. lobbii, B. subumbellatum and B. virescens. Malesian Orchid J. 8, 103-110.

Peakall, R., Ebert, D., Poldy, J., Barrow, R.A., Francke, W., Bower, C.C., Schiestl, F.P., 2010. Pollinator specificity, floral odour chemistry and the phylogeny of Australian sexually deceptive Chiloglottis orchids: implications for pollinator-driven speciation. New Phytol. 188, 437-450.

Peter, C.I., Johnson, S.D., 2014. A pollinator shift explains floral divergence in an orchid species complex in South Africa. Ann. Bot. 113, 277-288.

Pokorny, T., Vogler, I., Losch, R., Schlütting, P., Juarez, P., Bissantz, N., Ramirez, S.R., Eltz, T., 2017. Blown by the wind: the ecology of male courtship display behavior in orchid bees. Ecology 98, 1140-1152.

Raguso, R., 2001. Floral scent, olfaction, and scent-driven foraging behaviour. In: Chittka, L, Thompson, J.D. (Eds.) Cognitive Ecology of Pollination, pp. 83-105. Cambridge University Press, Cambridge, UK.

Renu, I.K., Haque, I., Kumar, M., Poddar, R., Bandopadhyay, R., Rai, A., Mukhopadhyay. K., 2014. Characterization and functional analysis of eugenol $O$-methyltransferase gene reveal metabolite shifts, chemotype specific differential expression and developmental regulation in Ocimum tenuiflorum L. Mol. Biol. Rep. 41, 1857-1870.

Ridley, H.N. 1890. On the method of fertilization in Bulbophyllum macranthum, and allied orchids. Ann. Bot. 4, $327-338$.

Royer, J.E., Agovaua, S., Bokosou,J., Kurika, K., Mararuai, A., Mayer, D. G., Niangu, B., 2018a. Responses of fruit flies (Diptera: Tephritidae) to new attractants in Papua New Guinea. Austr. Entomol. 57, 40-49.

Royer, J.E., Khan, M., Mayer, D.G., 2018b. Methyl-isoeugenol, a highly attractive male lure for the cucurbit flower pest Zeugodacus diversus (Coquillett) (syn. Bactrocera diversa) (Diptera: Tephritidae:Dacinae) J. Econ. Entomol. 111 (3), 1197-1201.

Schiestl, F.P., Dötterl, S., 2012. The evolution of floral scent and olfactory preferences in pollinators, Coevolution or pre-existing bias? Evolution 66, 2042-2055.

Schiestl, F., Johnson, S.D., 2013. Pollinator-mediated evolution of floral signals. Trends Ecol. Evol. 28, 307-315

Shelly, T.E., 2010. Effects of methyl eugenol and raspberry ketone/cue lure on the sexual behavior of Bactrocera species (Diptera: Tephritidae). Appl. Entomol. Zool. 45, 349-361.

Shuttleworth, A., Johnson, S.D., 2009. The importance of scent and nectar filters in a specialized wasppollination system. Funct. Ecol. 23, 931-940.

Smith, P.T., Kambhampati, S., Armstrong, K.A., 2003. Phylogenetic relationships among Bactrocera species (Diptera: Tephritidae) inferred from mitochondrial DNA sequences. Mol. Phylogenet. Evol. 26, 8-17.

Taberlet, P., Gielly, L., Pautou, G., Bouvet, J. 1991. Universal primers for amplification of three non-coding regions of chloroplast DNA. Plant Mol. Biol. 17, 1105-1109.

Tamura, K., Peterson, D., Peterson, N., Stecher, G., Nei, M., Kumar, S., 2011. MEGA5: Molecular evolutionary genetics analysis using maximum likelihood, evolutionary distance, and maximum parsimony methods. Mol. Biol. Evol. 28, 2731-2739.

Tan, K.H., Nishida, R., 1998. Ecological significance of a male attractant in the defence and mating strategies of the fruit fly pest, Bactrocera papayae. Entomol. Exp. Appl. 89, 155-158.

Tan, K.H., Nishida, R., 2000. Mutual reproductive benefits between a wild orchid, Bulbophyllum patens, and Bactrocera fruit flies via a floral synomone. J. Chem. Ecol. 26, 533-546.

Tan, K.H., Nishida, R., 2005. Synomone or Kairomone? - Bulbophyllum apertum (Orchidaceae) flower releases raspberry ketone to attract Bactrocera fruit flies. J. Chem. Ecol. 31, 509-519.

Tan, K.H., Nishida, R., 2007. Zingerone in the floral synomone of Bulbophyllum baileyi (Orchidaceae) attracts Bactrocera fruit flies during pollination. Biochem. Syst. Ecol. 35, 334-341. 
Tan, K.H., Nishida, R., 2012. Methyl eugenol: Its occurrence, distribution, and role in nature, especially in relation to insect behavior and pollination. J. Insect. Sci. 12, 1-60.

Tan, K.H., Nishida, R. 2013. Pollination of Bactrocerophilous Bulbophyllum Orchids. In: Elliott, J, Kurzweil, H.F., O'Byrbe, P., Tan, K.W., van der Schans, A.S., Wong, S.M., Yam, T.W. (Eds.) Proceedings of the 20th World Orchid Conference: Where new and old orchids meet. pp 273-279. Singapore Botanic Gardens, 2013.

Tan, K.H., Nishida, R., Toong, Y.C., 2002. Floral synomone of a wild orchid, Bulbophyllum cheiri, lures Bactrocera fruit flies for pollination. J. Chem. Ecol. 28, 1161-1172.

Tan, K.H., Tan, L.T., Nishida, R., 2006. Floral phenylpropanoid cocktail and architecture of Bulbophyllum vinaceum orchid in attracting fruit flies for pollination. J. Chem. Ecol. 32, 2429-2441.

Tan, K.H., Nishida, R., Jang, E.B., Shelly, T.E., 2014. Pheromones, male lures, and trapping of tephritid fruit flies. In: Shelly T.E., Epsky, N., Jang, E.B., Flores, J.R., Vargas, R. (Eds.) Trapping and the detection, control, and regulation of tephritid fruit flies. pp. 15-74. Springer, New York.

Van der Niet, T., Peakall, R., Johnson, S.D., 2014. Pollinator-driven ecological speciation in plants: New evidence and future perspectives. Ann. Bot. 113, 199-211.

Vermeulen, J.J., 2002. Bulbophyllum praetervisum J.J. Verm. (Orchidaceae), an overlooked species close to $B$. macranthum. Garden Bull. Singapore 54, 153-154.

Vogt, T., 2010. Phenylpropanoid biosynthesis. Mol. Plant. 3, 2-20.

Wee, S.L., Tan, K.H., 2001. Allomonal and hepatotoxic effects following methyl eugenol consumption in Bactrocera papayae male against Gekko monarchus. J. Chem. Ecol. 27, 953-964.

Wee, S.L., Tan, K.H., Nishida, R., 2007. Pharmacophagy of methyl eugenol by males enhances sexual selection of Bactrocera carambolae (Diptera: Tephritidae). J. Chem. Ecol. 33, 1272-1282.

Wee, S.L., Abdul Munir, M.Z., Hee, A.K.W., 2018. Attraction and consumption of methyl eugenol by male Bactrocera umbrosa Fabricius (Diptera: Tephritidae) promotes conspecific sexual communication and mating performance. Bull. Entomol. Res. 108, 116-124.

Zimmermann, Y., Roubik, D.W., Eltz, T., 2006. Species-specific attraction to pheromonal analogues in orchid bees. Behav. Ecol. Sociobiol. 60, 833-843.

Nakahira et al. 
Floral Synomone Diversification of Bulbophyllum Sibling Species (Orchidaceae) in Attracting Fruit Fly Pollinators

\section{Supplementary Materials}

Table S1

Table S2

Fig. S1

Fig. S2

Video S1 (submitted separately) 
Table S1. Sample records for flowers of Bulbophyllum macranthum and Bu. praetervisum

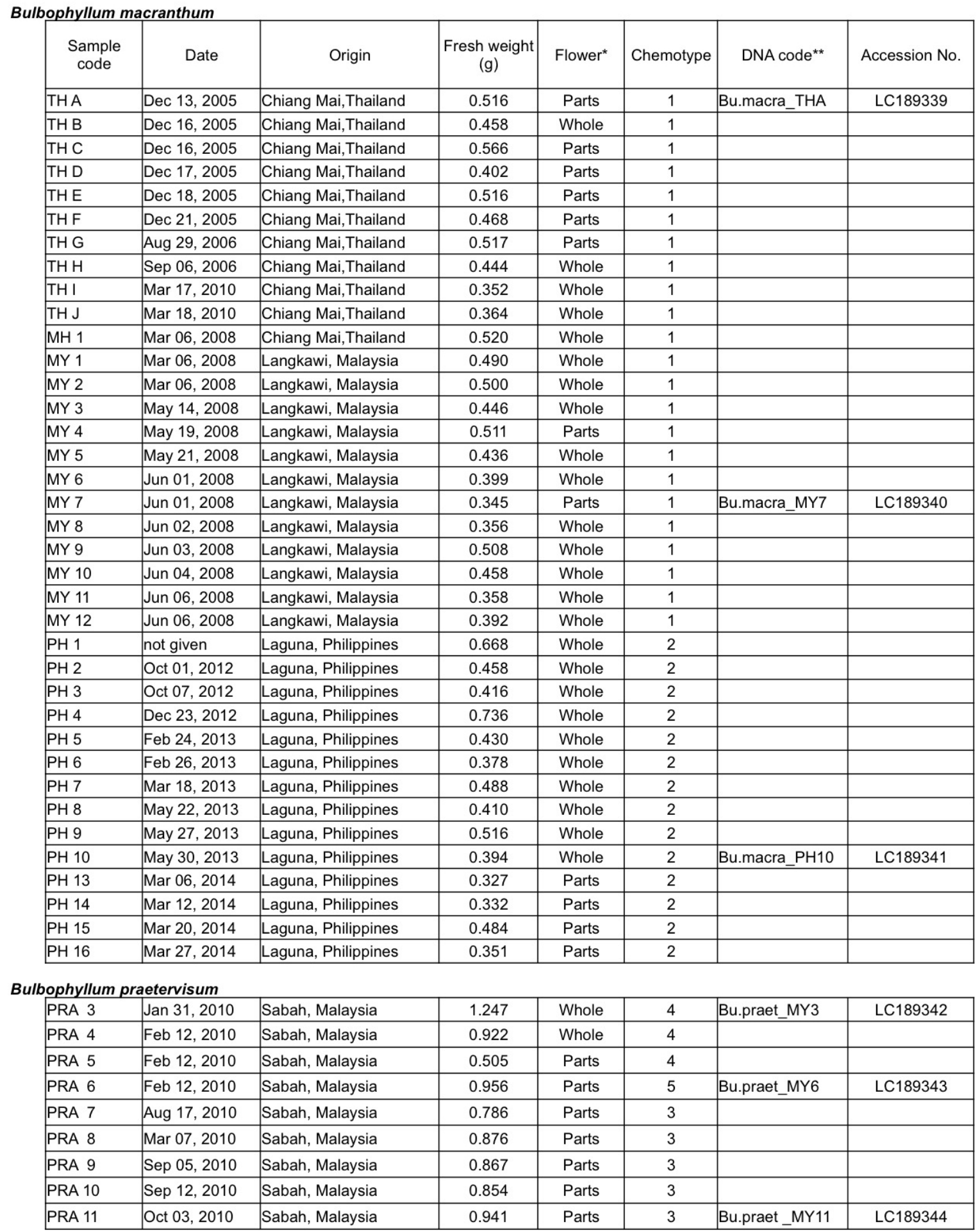

${ }^{\star}$ Flowers were weighed and chemically analyzed either as a whole flower or each floral part separately. ${ }^{* *}$ see Fig. 8 
Table S2. GC retention time and mass fragmentation of floral volatiles identified from floral samples*

\begin{tabular}{|l|l|c|l|}
\hline Compound & Source (Type) & $\begin{array}{l}\text { GC retention } \\
\text { time (min) }\end{array}$ & Mass fragments [m/z (\%)] \\
\hline Eugenol (EU) & $\begin{array}{l}\text { Bu. macranthum } \\
\text { Chemotype 2 }\end{array}$ & 12.54 & $\begin{array}{l}164(100), 149(35), 137(22), 131(22), 121(16), \\
103(30), 91(22), 77(31), 71(15), 55(19), 43(15)\end{array}$ \\
\hline Methyl eugenol (ME) & $\begin{array}{l}\text { Bu. macranthum, } \\
\text { Chemotype 2 }\end{array}$ & 13.12 & $\begin{array}{l}178(100), 163(30), 147(31), 135(10), 115(11), \\
107(25), 103(28), 91(34), 77(18), 65(13), 51 \\
(10), 41(10)\end{array}$ \\
\hline (E)-Methyl isoeugenol & $\begin{array}{l}\text { Bu. macranthum, } \\
\text { Chemotype 2 }\end{array}$ & 14.41 & $\begin{array}{l}178\left(100, \mathrm{M}^{+}\right), 163(45), 147(12), 107(28), 103 \\
(18), 91(22), 77(15)\end{array}$ \\
\hline Raspberry ketone (RK) & $\begin{array}{l}\text { Bu. praetervisum, } \\
\text { Chemotype 3 }\end{array}$ & 15.06 & $\begin{array}{l}164(41), 149(7), 121(13), 107(100), 94(13), 91 \\
(9), 77(17), 65(6), 43(24)\end{array}$ \\
\hline Rhododendrol (RL) & $\begin{array}{l}\text { Bu. praetervisum, } \\
\text { Chemotype 3 }\end{array}$ & 15.22 & $\begin{array}{l}166(30), 148(23), 133(86), 107(100), 94(13), 77 \\
(23), 65(7), 45(10)\end{array}$ \\
\hline Zingerone (ZN) & $\begin{array}{l}\text { Bu. macranthum, } \\
\text { Chemotype 1 }\end{array}$ & 16.20 & $\begin{array}{l}194(47), 151(13), 137(100), 119(17), 91(15), 77 \\
(8), 43(19)\end{array}$ \\
\hline Zingerol (ZL) & $\begin{array}{l}\text { Bu. macranthum, } \\
\text { Chemotype 1 }\end{array}$ & 16.51 & $\begin{array}{l}196(51), 178(8), 163(17), 151(7), 147(8), 138 \\
(56), 137(100), 131(32), 122(16), 119(11), 107 \\
(12), 94(10), 91(17), 77(12), 65(8), 43(13)\end{array}$ \\
\hline
\end{tabular}

*The data was obtained with an Agilent 5975 mass spectrometer coupled with an Agilent $6890 \mathrm{~N}$ gas chromatograph [HP-5MS capillary column, 5\% phenyl methyl siloxane $(30 \mathrm{~m} \times 0.25 \mathrm{~mm}, 0.25 \mathrm{~mm}$ film thickness), programmed from $60^{\circ}(2 \mathrm{~min}$ holding $)$ to $290^{\circ} \mathrm{C}$ at a rate of $10^{\circ} \mathrm{C} / \mathrm{min}$, total ion monitor]. 


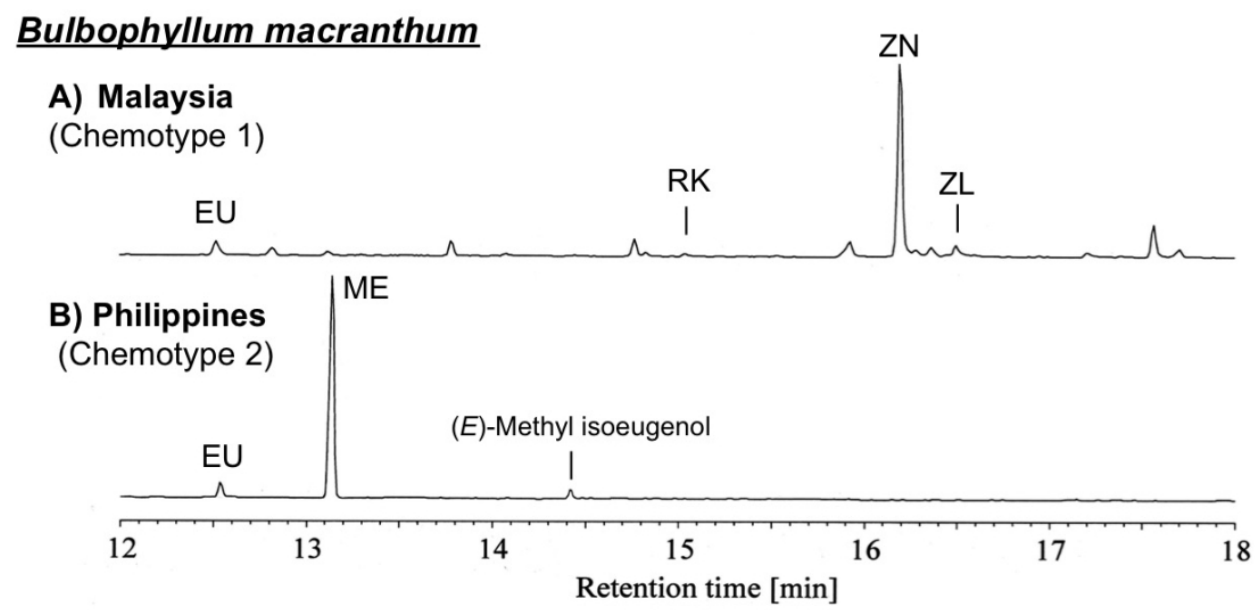

\section{Bulbophyllum praetervisum}

C) Malaysia

(Chemotype 4)
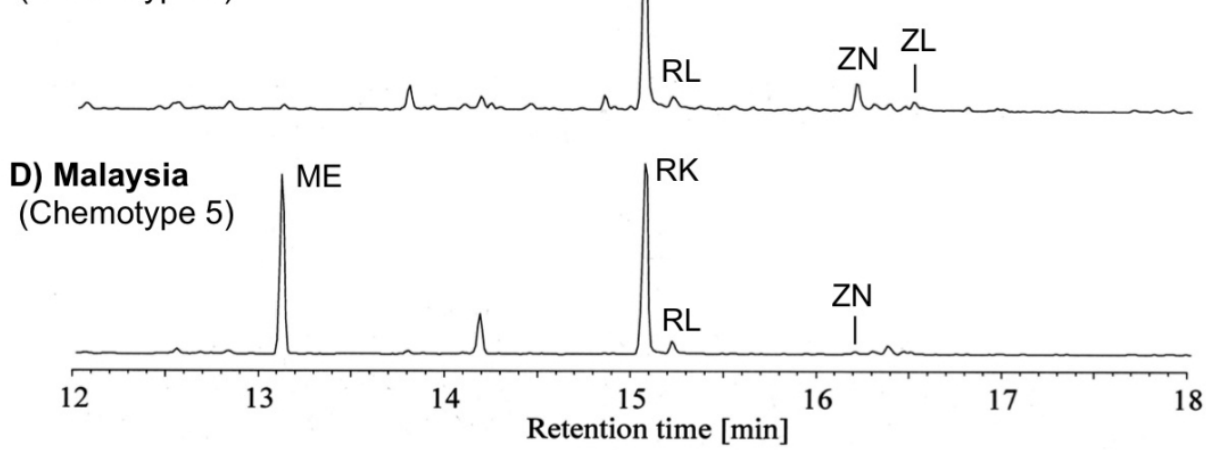

Fig. S1. Gas chromatogram of floral extract of a fruit fly orchid, A) Bulbophyllum macranthum (Langkawi, Malaysia) (Chemotype 1), B) Bu. macranthum (Laguna, Philippines) (Chemotype 2), C) Bu. praetervisum (Sabah, Malaysia) (Chemotype 4) and D) Bu. praetervisum (Sabah, Malaysia) (Chemotype 5) [MS total ion current: HP-5MS, cross-linked 5\% PH ME siloxane, $30 \mathrm{~m} \times 0.25 \mathrm{~mm}$, $0.25 \mu \mathrm{m}$ film thickness, programmed from $60^{\circ} \mathrm{C}(2 \mathrm{~min}$ holding $)$ to $290^{\circ} \mathrm{C}$ at a rate of $\left.10^{\circ} \mathrm{C} / \mathrm{min}\right]$. EU: eugenol, ME: methyl eugenol, RK: raspberry ketone, RL: rhododendrol, ZN: zingerone, ZL: zingerol. 


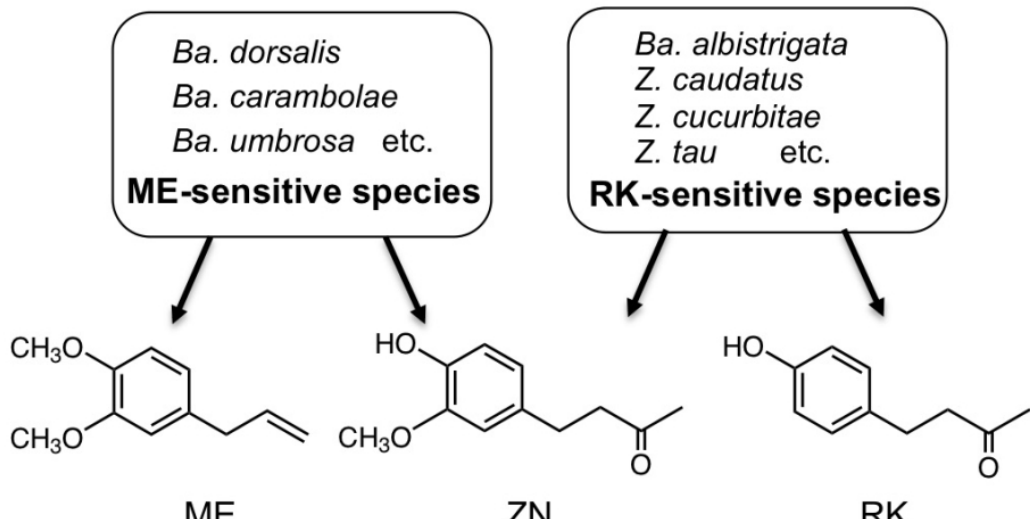

\begin{tabular}{lccc}
\hline Orchid species/type & $\begin{array}{c}\text { Methyl eugenol } \\
(\mathrm{ME})\end{array}$ & $\begin{array}{c}\text { Zingerone } \\
(\mathrm{ZN})\end{array}$ & $\begin{array}{c}\text { Raspberry ketone } \\
(\mathrm{RK})\end{array}$ \\
\hline $\begin{array}{l}\text { Bu. macranthum } \\
\text { Thailand (Chemotype 1) }\end{array}$ & - & ++ & - \\
$\begin{array}{l}\text { Bu. macranthum } \\
\text { Malaysia (Chemotype 1) }\end{array}$ & - & ++ & \pm \\
$\begin{array}{l}\text { Bu. macranthum } \\
\text { Philippines (Chemotype 2) }\end{array}$ & +++ & - & - \\
\hline $\begin{array}{l}\text { Bu. praetervisum } \\
\text { Malaysia (Chemotype 3) }\end{array}$ & - & - & +++ \\
$\begin{array}{l}\text { Bu. praetervisum } \\
\text { Malaysia (Chemotype 4) }\end{array}$ & - & + & ++ \\
Bu. praetervisum & & + & +++ \\
Malaysia (Chemotype 5) & ++ & + & + \\
\hline
\end{tabular}

Fig. S2. A summary of major floral synomone constituents among local chemotypes in two sibling species, Bulbophyllum macranthum and Bu. praetervisum, and potential pollinator fruit fly species classified by the affinities to floral chemicals: methyl eugenol (ME), raspberry ketone (RK) and zingerone (ZN) [relative abundances,,++++++ and $\pm ;-$ not detected; see also Fig. 4 and Table 1]. 


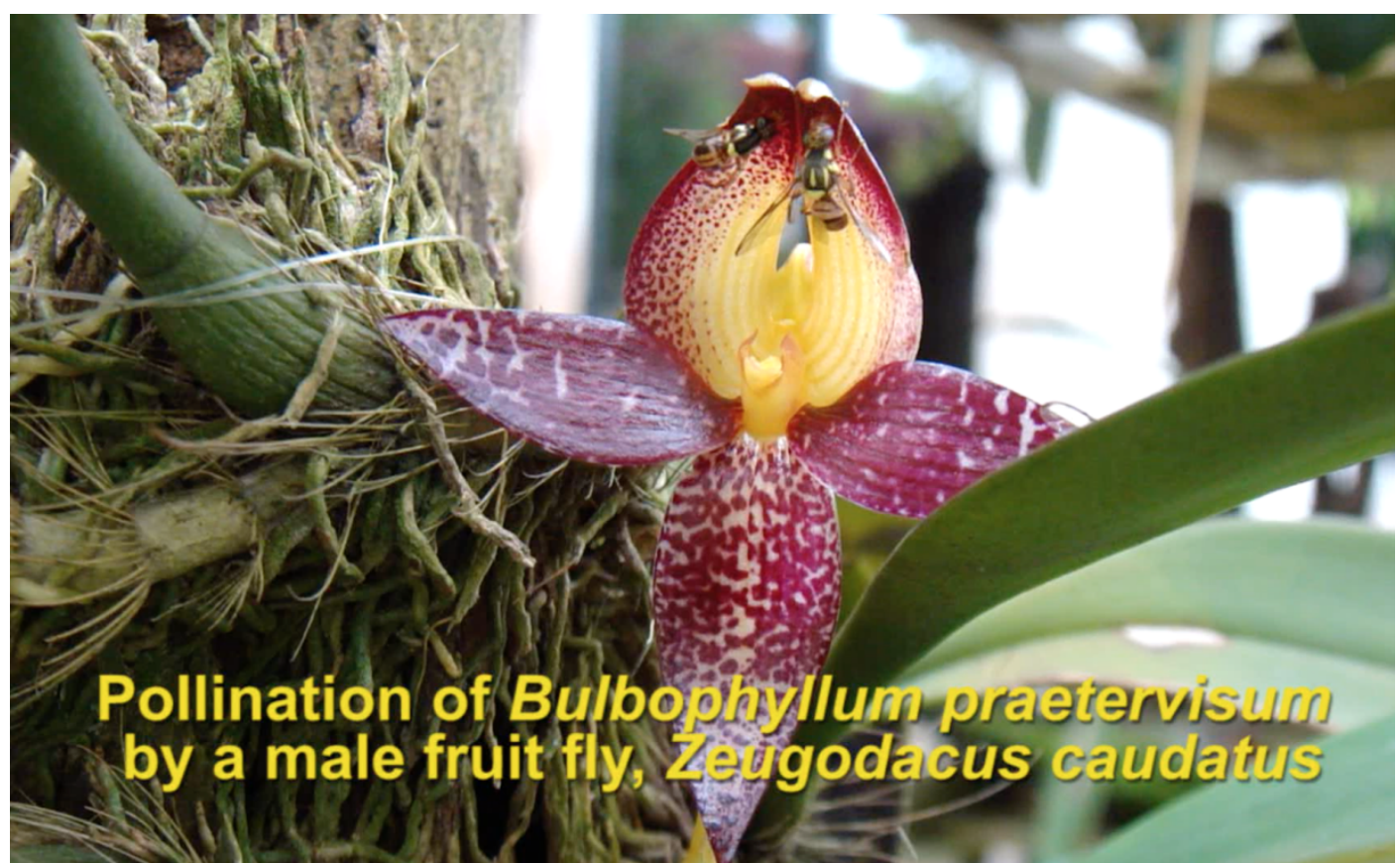

Video S1. Pollinia deposition onto the stigma during pollination of Bulbophyllum praetervisum by a male fruit fly, Zeugodacus caudatus. 